\title{
CHARACTERISTICS OF ALUMINUM FOAM UNDER DIFFERENT LOADING RATES
}

\author{
A . A .Hussein ${ }^{1,}$, W. M. Khairaldien ${ }^{2}$, A. A . Khalil ${ }^{3}$, A. A. Nasser ${ }^{4}$ \\ Department of Mechanical Engineering, Faculty of Engineering , Assiut University, Assiut, Egypt
}

Received 19 May 2013; accepted 30 July 2013

\begin{abstract}
In this paper aluminum foam was produced using pure aluminum powder and calcium carbonate as foaming agent. This procedure ensures a low cost production method. Samples of aluminum foam were tested under both static and dynamic loading conditions. The quasi-static compression tests were used to evaluate the static characterization of aluminum foam. Hopkinson pressure bar arrangement was used to study dynamic properties of the produced material under high strain rates. The comparison between static and dynamic results shows that the specimen toughness increases with loading rates. Relative density increase produce a drop in absorbed energy in dynamic ranges of loading while in static loading condition the opposite of this relation obtained between relative density and energy.
\end{abstract}

Keywords: Split Hopkinson pressure for aluminum foam shockwave.

\section{Introduction}

Metal foam is a cellular structure consisting of metal frequently aluminum - containing a large volume fraction of gas-filled pores. The pores can be sealed (closed-cell foam), or they can form an interconnected network (open-cell foam). The defining characteristic of metal foams is a very high porosity typically $75-95 \%$ of the volume consists of void spaces. The strength of foamed metal possesses a power law relationship to its density. Aluminum foam is made from molten aluminum by stabilizing bubbles in the melt using both suitable foaming agent and temperature control. Aluminum foams have the potential to be used as structural material for impact energy absorption applications due to their extended constant stress region during compression. When it used as cores of structural sandwich panels, it give high stiffness with high sound absorption capacity and low thermal conductivity. It can also be used as vibration absorbers and heat exchangers [1]. Many distinct process-routes have been developed to make metal foams [2, 3 ]. Metallic foams can also be produced by melt foaming process [4 -6]. In this fabrication technique , some viscosity increasing agents such as $\mathrm{SiC}, \mathrm{SiO}_{2}, \mathrm{MgO}$ and $\mathrm{Al}_{2} \mathrm{O}_{3}$ particles are added to the metallic melt in order to make the melt get an appropriate viscosity. It was suggested that the viscosity increasing agent not only stabilized the cell wall but also affected the mechanical properties of the foams [6-12]. TiH2 is the most popular foaming agent [2-6], but the relatively new trend in metallic foam production used the calcium carbonate as a foaming agent $[9,15]$. The carbonate decomposes within the molten metal and foams $\mathrm{CaO}$ solids and the reactive gas $\mathrm{CO}_{2}$. Under conditions of aggressive agitation, the gas bubbles formed within the molten metal are ruptured and fragmented, exposing more of the reactive gas to the molten metal. This gas reacts with the molten aluminum foaming $\mathrm{CO}$ gas and in-situ formed $\mathrm{AI}_{2} \mathrm{O}_{3}$. The $\mathrm{CO}$ and $\mathrm{CO}_{2}$ gas bubbles, as well as $\mathrm{AI}_{2} \mathrm{O}_{3}, \mathrm{CaO}$ and

Corresponding author.

E-mail address: eyeten2013@yahoo.com 
A. A. Hussein, et al., Characteristics of Aluminum Form under Different Loading Rates, pp. 1830 - 1841 other metallic oxide phases, stabilize the liquid metal suspension by modifying the viscosity and surface energy of the molten metal $[14,15]$. In this work specimen made from aluminum foam produced using calcium carbonate as a foaming agent, was subjected to both dynamic and static loading rates to characterize its mechanical behavior under different loading rates.

\section{Experimental Procedure}

\section{1. Specimen preparation}

Specimens made from aluminum foam produced using calcium carbonate, as foaming agent in a process similar to the process of producing aluminum foam using titanium hydride as foaming agent. This process is very cheap compared to the regular process. Special cylindrical controllable furnace was used during the process in which the aluminum melt is poured followed by continuous stirring at $1500 \mathrm{rpm}$. Aluminum oxide powder was added as stabilizing agent followed by calcium carbonate powder and as the stirring continue the aluminum start to foam until it reaches the required volume in a complicated process. Stirring speed, temperature and time are the parameters used to control the produced foam relative density that was studied in a previous work [16]. The following procedure was adapted through the current work. About $500 \mathrm{gm}$ of the commercial pure aluminum was melted, a cylindrical steel mould coated with a thin layer of anti-sticking material (commercial calcium carbonate) using spray atomizer was used. The coated steel mould was then inserted into the foaming furnace . The temperature of molten metal was adjusted between 675 and $775^{\circ} \mathrm{C}$ and $\mathrm{Al} 2 \mathrm{O} 3$ powder was added, the mix was then stirred with stainless steel mixer to keep the efficient uniform distribution of alumina particles in the molten aluminum at $1500 \mathrm{rpm}$ for about one minute. Then, the mixer speed is adapted at $2000 \mathrm{rpm}$ and the foaming agent (CaCO3) is added and mixed. The mixing process was carried out in the furnace at temperature between $675-775^{\circ} \mathrm{C}$ adjusted by control system. The mould was then taken out and air cooled. Samples were cylinder having a height of approximately $155 \mathrm{~mm}$ and diameter of $85 \mathrm{~mm}$. The samples were cut into circular slices of 2 thicknesses each. The materials used during the process were as follow:

Commercial pure aluminum $(99.86 \% \mathrm{Al})$ supplied by the aluminum company of Egypt, and Foaming agent: Calcium carbonate powder, supplied by (El Gomhouria Co.), the purity of powder is $(99 \%)$.

\section{2. Quasi-static compression test}

The relative density $\rho^{*} / \rho s$ (defined as the density of the foam divided by the density of the solid ) of the foams ranged from 0.18 to 0.317 . Experiments were carried out on a 1000-kN universal testing machine, (Tinios Olsen Machine) Model 290 Display with a data acquisition device, Fig(1). Data acquisition was performed using a system composed of a computer, a data acquisition card and application software, which performs the A/D conversion. The relationship of load and displacement is plotted and displayed directly on screen and saved on an Excel work sheet for later manipulation.

Journal of Engineering Sciences, Assiut University, Faculty of Engineering, Vol. 41, No. 5, September, 2013, E-mail address: jes@aun.edu.eg 


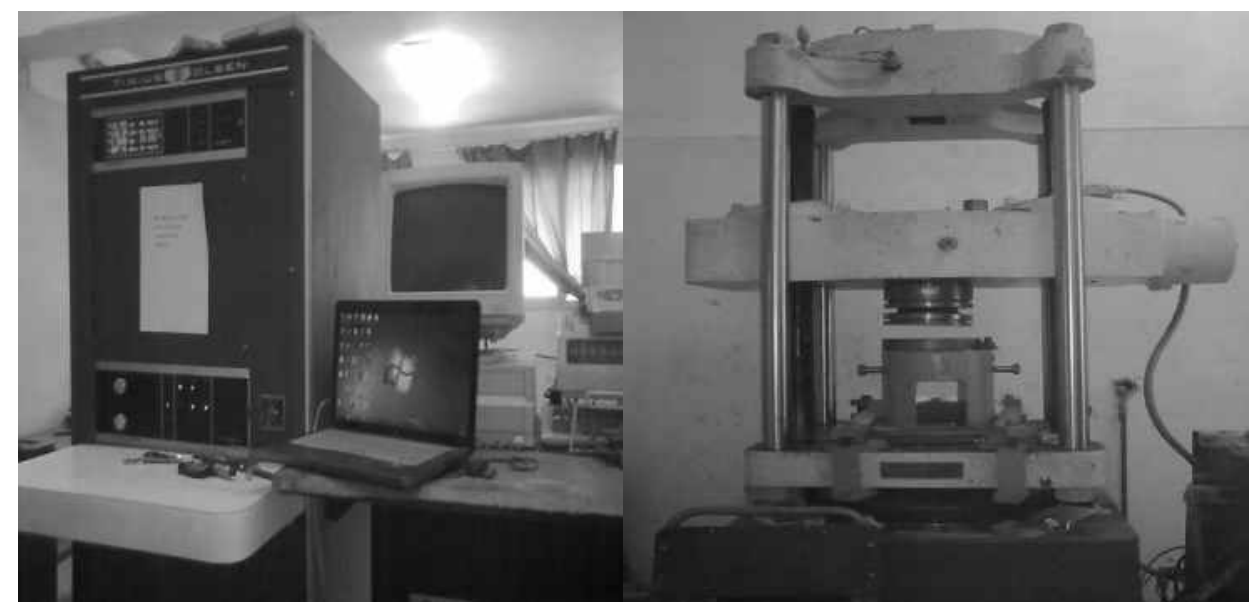

Fig. 1. Tinios Olsen Machine Model 290

The foam specimen was compressed between two steel plates on and crushed from initial height of $20 \mathrm{~mm}$ along the thickness. Ten specimens with different densities were tested .The stress was calculated by dividing the load over the total cross sectional area, and the engineering strain was calculated from the cross-head displacement. The plateau stress was taken as the average stress at $20 \%$ strain during compression . The energy absorption per unit volume, W was computed by evaluating the area under the stress-strain curve [ 17 ].

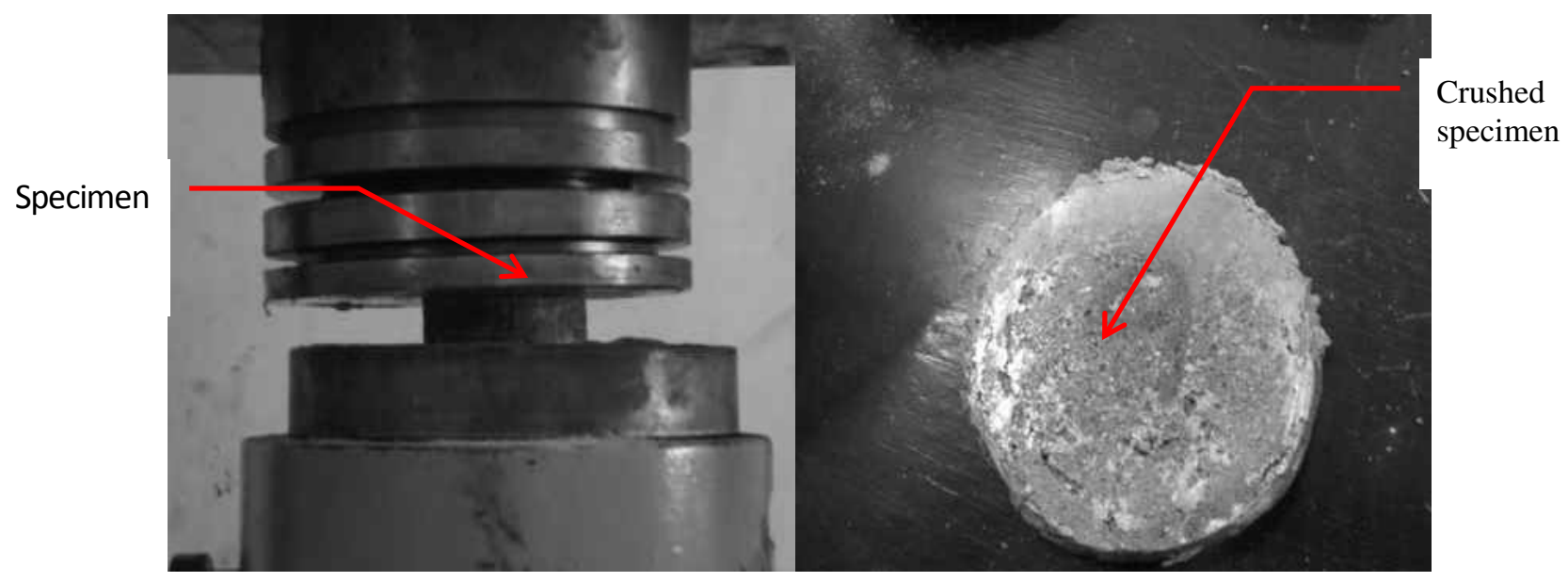

Fig. 2. Compression test and specimen at the end of test

During the test the upsetting process did not cause specimen breaking but the billet pressed itself and a gradual external surface flaking was observed as shown in $\operatorname{Fig}(2)$.

\section{Dynamic Test}

Hopkinson split pressure bar is the only test apparatus that can cover the range of dynamic loading that needs to be studied with adequate accuracy because of the nature of

Journal of Engineering Sciences, Assiut University, Faculty of Engineering, Vol. 41, No. 5, September, 2013, E-mail address: jes@aun.edu.eg 
its measuring system that element stress wave superposition opportunity. A compressive stress wave is generated and then propagates towards the specimen, moving the bar material towards the specimen. When the wave arrives at the interface between the incident bar and the specimen, part of the wave is reflected back into the incident bar towards the impact end and the rest transmits through the specimen into the transmission bar. Laboratory instrumentation shown in Fig. (3) Can record the stress waves in the incident bar propagating towards the specimen and being reflected back from the specimen and the wave in the transmission bar. Under this arrangement the impact event is controllable and quantitative. The impact velocity and specimen size may be varied to achieve different strain rates. Further analysis on the waves recorded in the impact event results in information regarding the loading conditions and deformation states in the specimen.

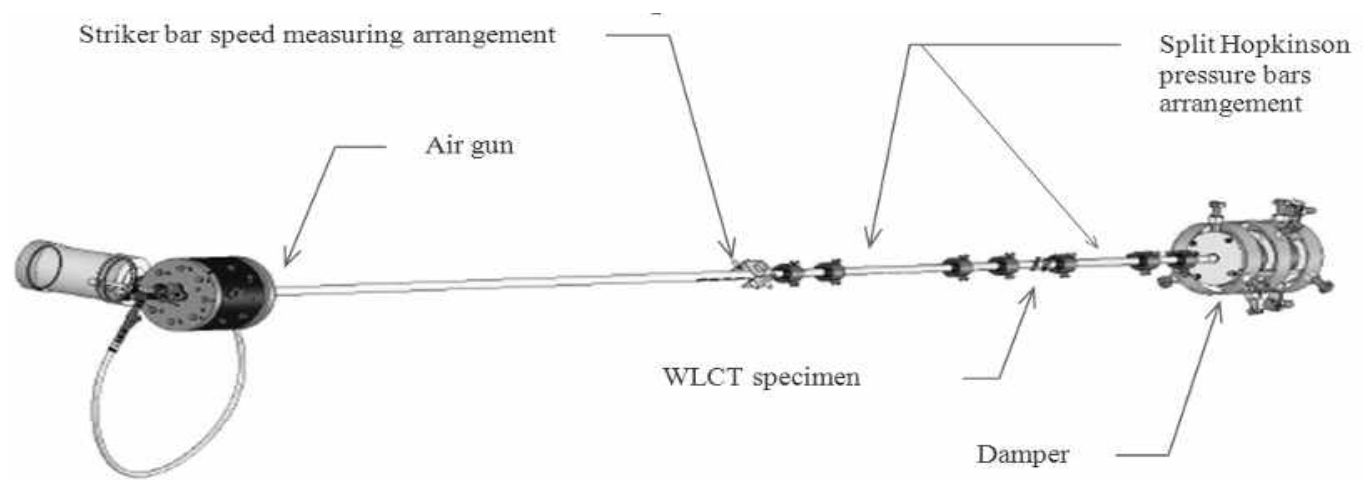

Fig. 3. Split Hopkinson pressure bar

The split Hopkinson pressure bar arrangement consists mainly of two bars namely; the incident bar and the transmitted bar. The two bars are made of high strength chromium steel with diameter of $40 \mathrm{~mm}$. The incident bar is 2 meter long to separate the incident compressive stress wave from the reflected tension stress wave. The incident bar transmits the stress wave from the striker bar to the front of the specimen. Error! Reference source not found. is shown in Fig. (4)The stress waves in the incident bar (incident and reflected) are monitored using strain gage station mounted at the middle of the bar. The transmitted bar is 1.5 meter long and used to support the back of the specimen.

The strain gauge stations attached to the incident and transmitted bars record three strain gauge signals namely $\varepsilon_{i}(t) \varepsilon_{r}(t)$ and $\varepsilon_{t}(t)$ which are the incident, the reflected and the transmitted strain waves respectively

By knowing the distance between the strain gauge station and specimen it is possible to calculate the time of beginning of each signal. The net displacement of the specimen can then be determined as:

$$
\delta(t)=\mu_{I}(t)-\mu_{T}(t)=C_{O} \int_{0}^{t}\left(\varepsilon_{I}(t)-\varepsilon_{R}(t)-\varepsilon_{T}(t)\right) d t
$$

Where

Journal of Engineering Sciences, Assiut University, Faculty of Engineering, Vol. 41, No. 5, September, 2013, E-mail address: jes@aun.edu.eg 
$\mathrm{CO} \quad$ is the elastic wave speed in the Hopkinson bars materials $=\sqrt{\frac{E}{\rho}}$

E is the Young modulus of the incident and transmitted bar material.

$\rho \quad$ is the bars material density.

Dimensional theory of elastic wave propagation as:

$\overline{P_{I}}(t)=\sigma_{I} \mathrm{~A}=\mathrm{EA}\left[\varepsilon_{I}(t)+\varepsilon_{R}(t)\right]$ and $\overline{P_{T}}(t)=\sigma_{T} \mathrm{~A}=\mathrm{EA} \varepsilon_{T}(t)$

And their average is:

$$
\bar{P}(t)=\frac{1}{2} E A\left[\varepsilon_{i}(t)+\varepsilon_{r}(t)+\varepsilon_{t}(t)\right]
$$

Where:

A is the cross section area of the bars

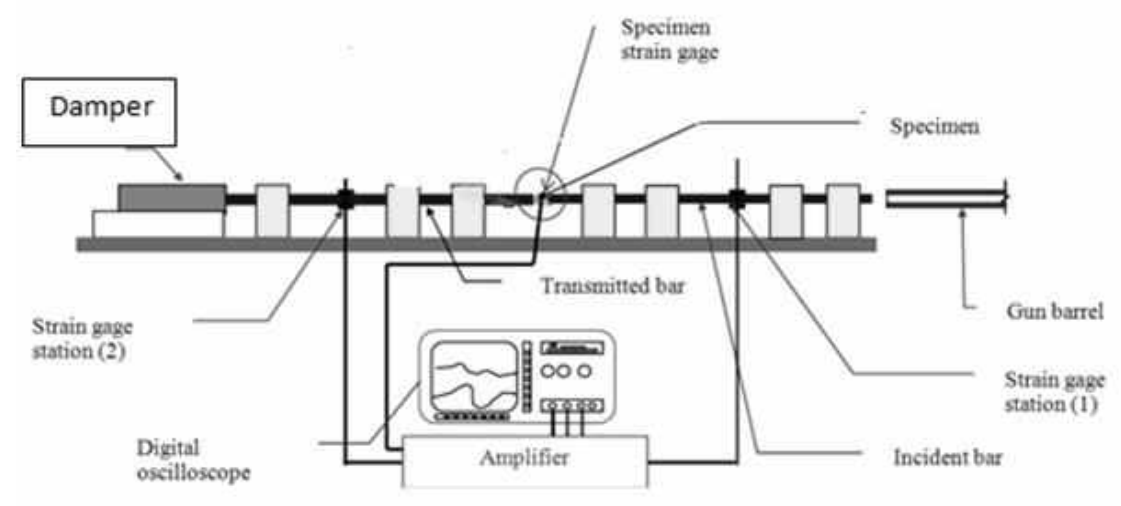

Fig. 4. Split Hopkinson pressure bar measuring system

The data acquisition system consists of:

Specially built three channel amplifier with built in 12 DC volt power supply

Digital oscilloscope with memory TDS-420A (Tektronix $200 \mathrm{MHz}$ maximum analog bandwidth; 100Mega-sample /second digitizing rate; 4 channels; attached floppy drive 1.44 MB) Fig. (5) Shows the Oscilloscope output during test.

The specimen was inserted at the end of the incident and transmitted bars using two flat jaws to position the specimen centrally between the bars. The air pressure was adjusted according to the required wave loading value. The system was triggered and the capture signal on using oscilloscope is to be saved and transferred to digital signal to the computer for farther processing. The recorded signal was transferred to strain using system calibration factor and then into load - displacement using equations 1:3.

Journal of Engineering Sciences, Assiut University, Faculty of Engineering, Vol. 41, No. 5, September, 2013, E-mail address: jes@aun.edu.eg 


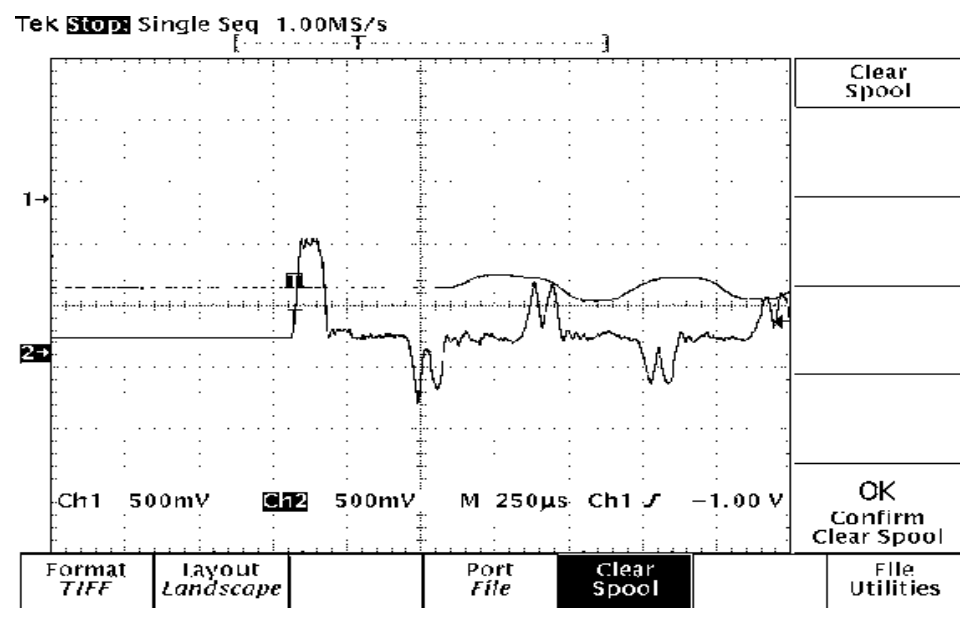

Fig. 5. Oscilloscope output during test

\section{Results and Discussion}

Specimens having relative density ranging from $\rho^{*} / \rho$ s $=0.17$ to 0.31 were tested under quasi-static and dynamic loading conditions. The quasi-static compressive stress-strain curves of aluminum foams, In Compressive stress-strain curves of ideal foam as shown in Fig (6) the exhibit universal three deformation regions: an initial linear-elastic response; an extended plateau region with a nearly constant flow stress, and a final densification as collapsed cells are compacted together. Experimental results also show that the foams with high relative density have higher stiffness and yield stress.

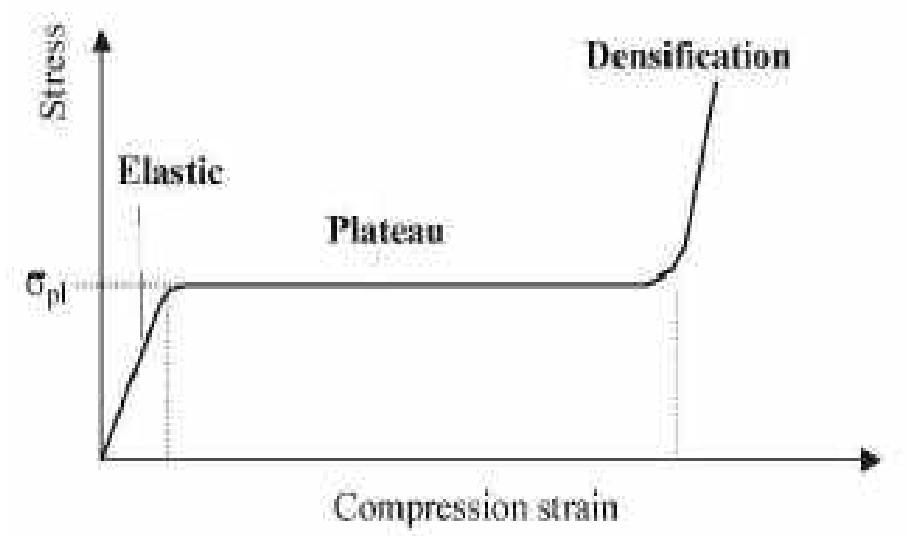

Fig. 6. Compressive stress-strain curves of ideal foam

Journal of Engineering Sciences, Assiut University, Faculty of Engineering, Vol. 41, No. 5, September, 2013, E-mail address: jes@aun.edu.eg 
A. A. Hussein, et al., Characteristics of Aluminum Form under Different Loading Rates, pp. 1830 - 1841

The Quasi-static compression load displacement curves for different densities of aluminum foam are shown in Fig (7). In which the same trend was obtained with slightly different specimen densities.

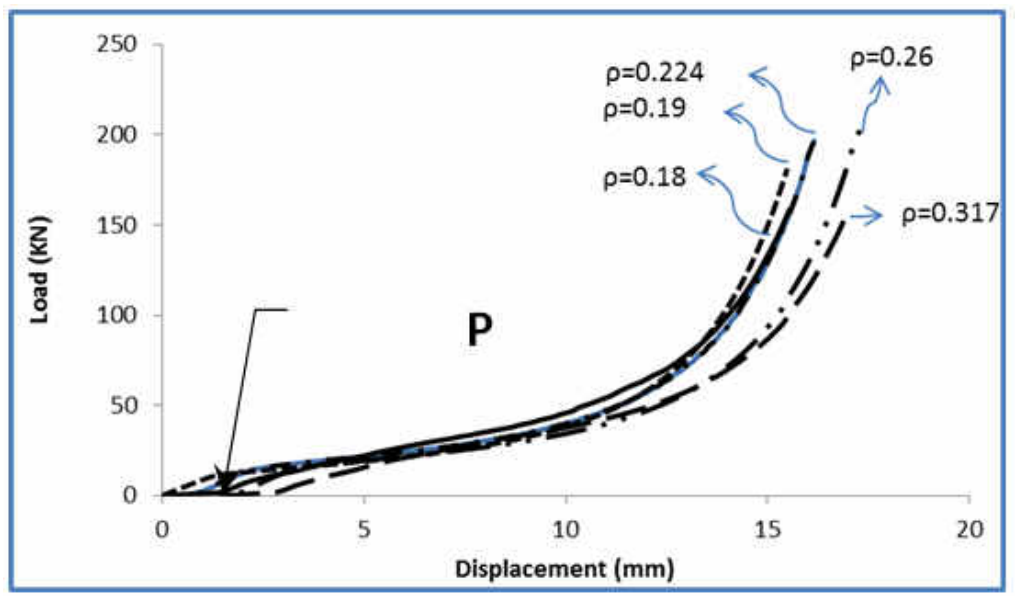

Fig. 7. load-displacement curves for aluminum foam with different densities in compression test.

The (load- displacement) curves recorded during dynamic test for different densities of aluminum foam are shown in Fig (8).

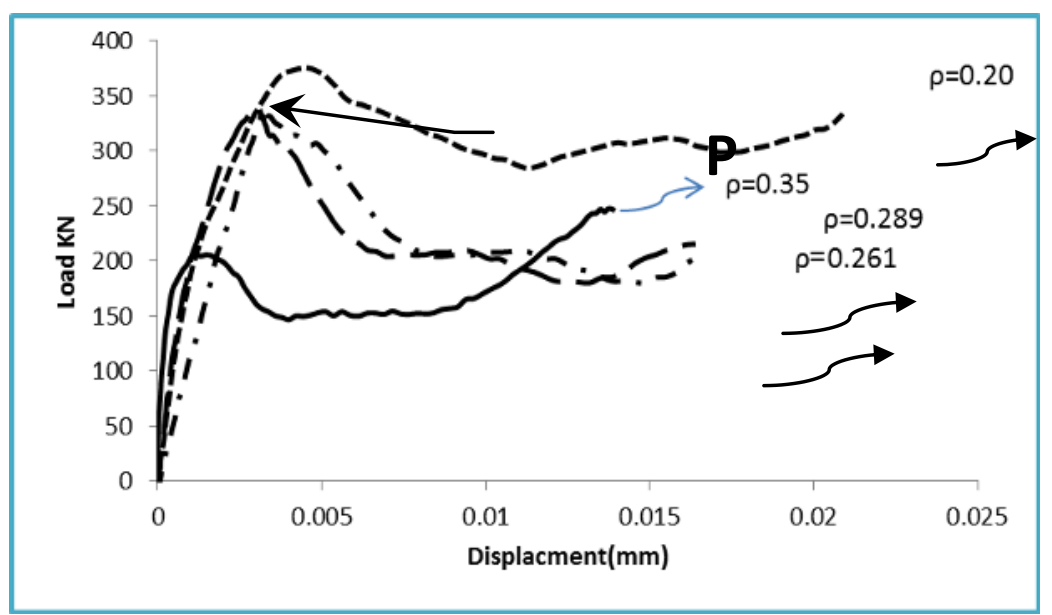

Fig. 8. the (load- displacement) curves for different densities of aluminum foam from dynamic test.

Journal of Engineering Sciences, Assiut University, Faculty of Engineering, Vol. 41, No. 5, September, 2013,E-mail address: jes@aun.edu.eg 


\section{A. A. Hussein, et al., Characteristics of Aluminum Form under Different Loading Rates, pp. 1830 - 1841}

From the load displacement curves for static and dynamic tests it can be seen that the maximum specimen load before failure in dynamic loading is four times the quasi-static loading condition as shown in Fig(9). While in case of dynamic loading no plateau stress region is remarkable. This is due to the high loading rate wave which crush the specimen gradually in a very short period of time. The load is raised forming a peak load before the load drops. This can be explained in Fig (10). The dynamic wave introduced into the specimen through the incident bar crush the first line of voids in the front of the specimen. This crush of voids produces a dispersion in the wave transferred to the walls of the voids. Also redirect the wave into small incident and reflected waves super positioned inside the walls that weak the major wave and increase the specimen load carrying capacity.

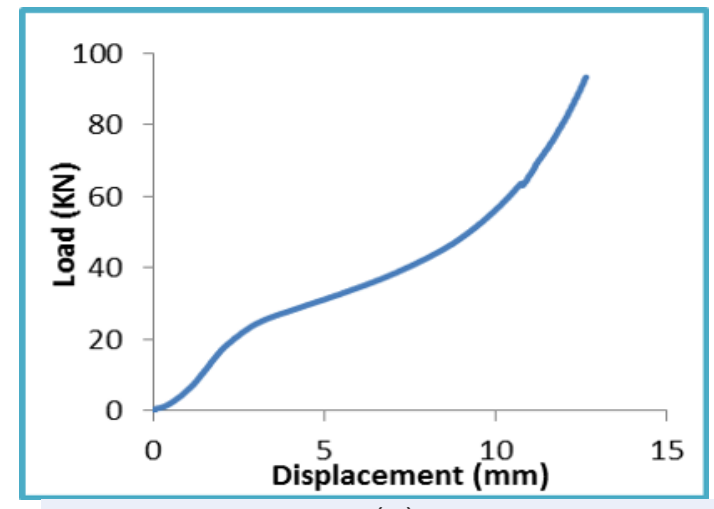

(a)

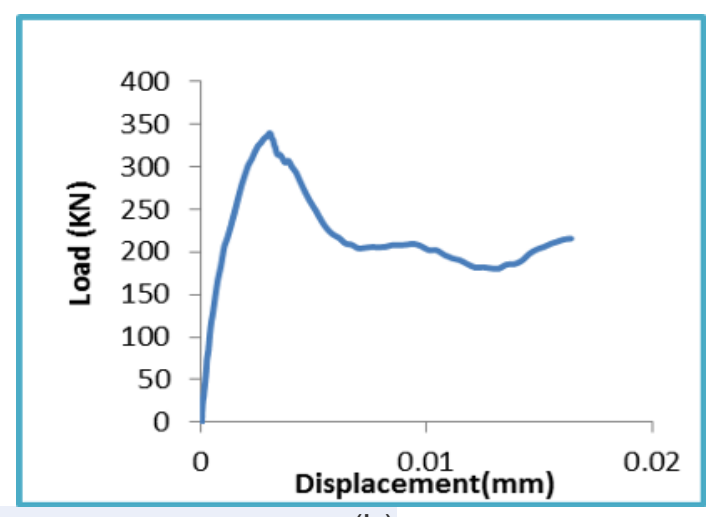

(b)

Fig. 9. Comparison between dynamic and static load displacement curves

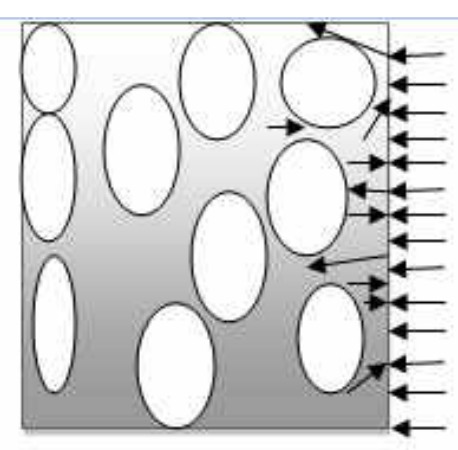

(a)

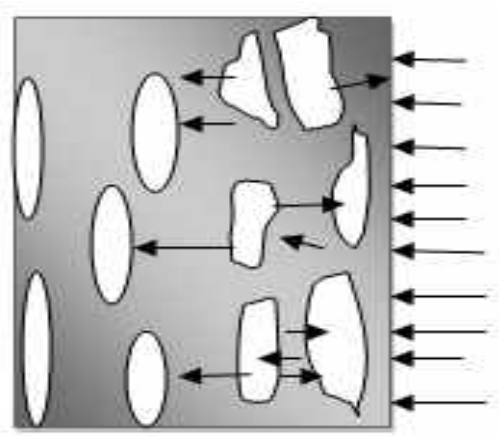

(b)

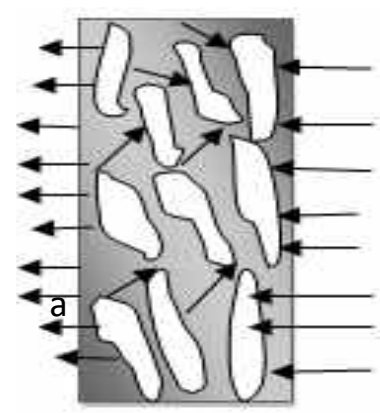

(c)

Fig. 10. Void failure mechanism during dynamic compression

Aluminum foam walls covered with aluminum oxide tend to be more hard as the loading rate increase, which rise the strength of material and consequently increase the material total load carrying capacity.

Journal of Engineering Sciences, Assiut University, Faculty of Engineering, Vol. 41, No. 5, September, 2013,E-mail address: jes@aun.edu.eg 
A. A. Hussein, et al., Characteristics of Aluminum Form under Different Loading Rates, pp. 1830 - 1841

This phenomena can be also realized from the output signal of aluminum foam specimen compared with solid specimen shown in Fig (11). In case of solid aluminum the reflected portion of the wave are slightly higher in magnitude and short in time. The major portion of the incident wave referring to minimum portion of energy to be absorbed.
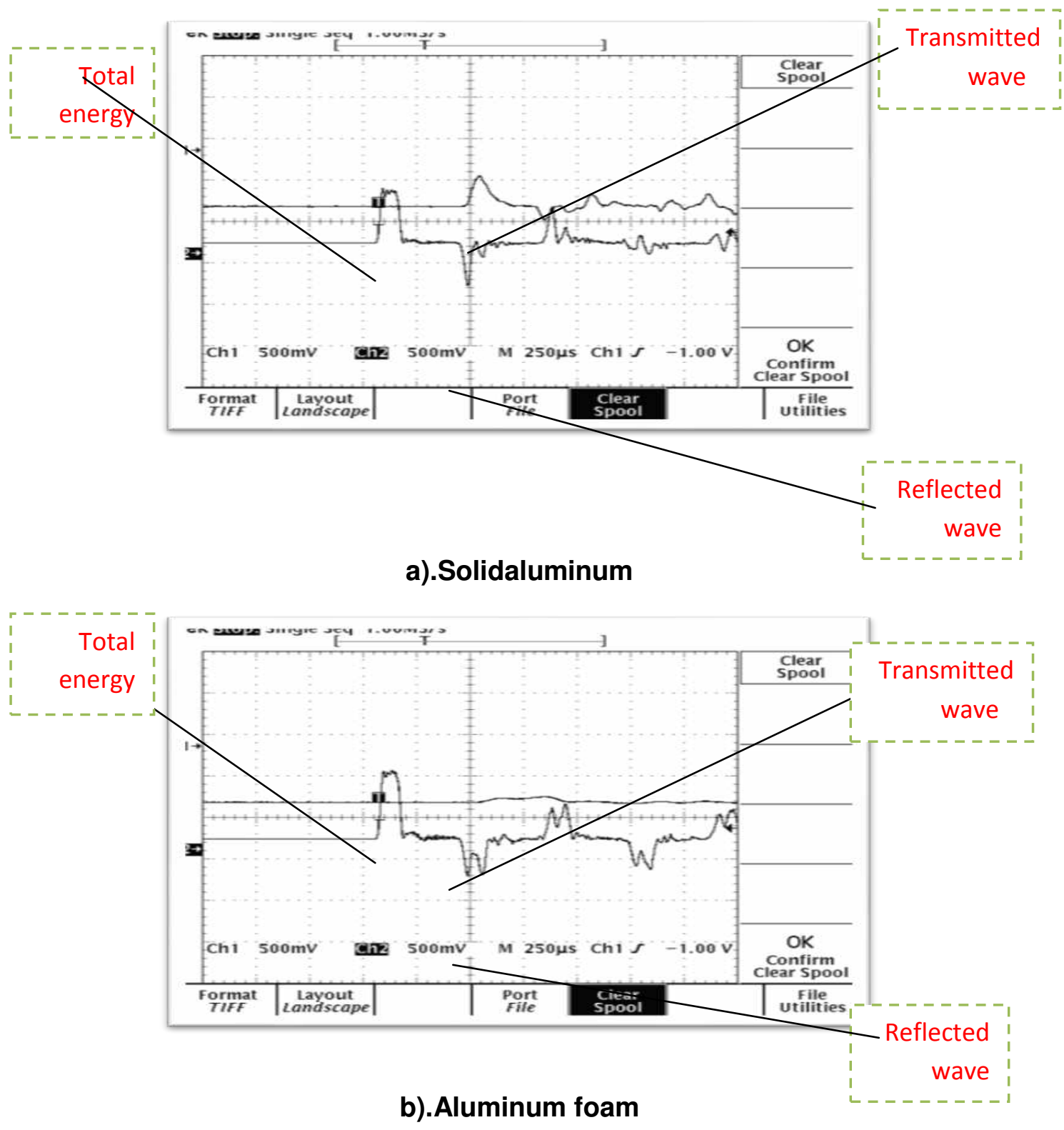

Fig.11. Comparison between reflected wave in aluminum foam specimen and solid aluminum specimen having the same dimensions

Journal of Engineering Sciences, Assiut University, Faculty of Engineering, Vol. 41, No. 5, September, 2013, E-mail address: jes@aun.edu.eg 
The energy absorbed in the material, which represents the area under the load displacement curve was calculated for both static and dynamic loading conditions. For the quasi-static test the energy absorbed by the specimen up to $20 \%$ plateau strain was plotted against relative density as shown in Fig (12). It is clear from the figure that the energy absorbed increases with the increases of for relative density greater than or equal 0.25 . This is due to the fact that static loading are slow enough to be distributed fairly among the whole surface and depth of the material. This means that dense material can carry more load.

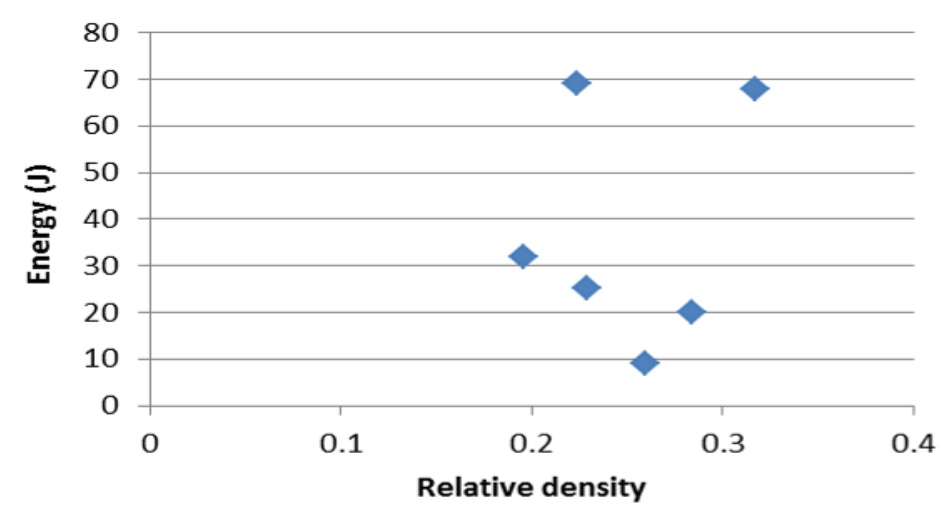

Fig. 12. Energy absorbed with relative density in static test

On the other hand, in the case of dynamic loading, the energy absorbed decreases with the increase for relative density greater than or equal 0.2 as shown in Fig(13) This is mainly due to the fact that, void percentage increase which produce an increase in the amount of wave dispersion among the voids. The voids wall increases the amount of energy absorbed in the material during dynamic loading.

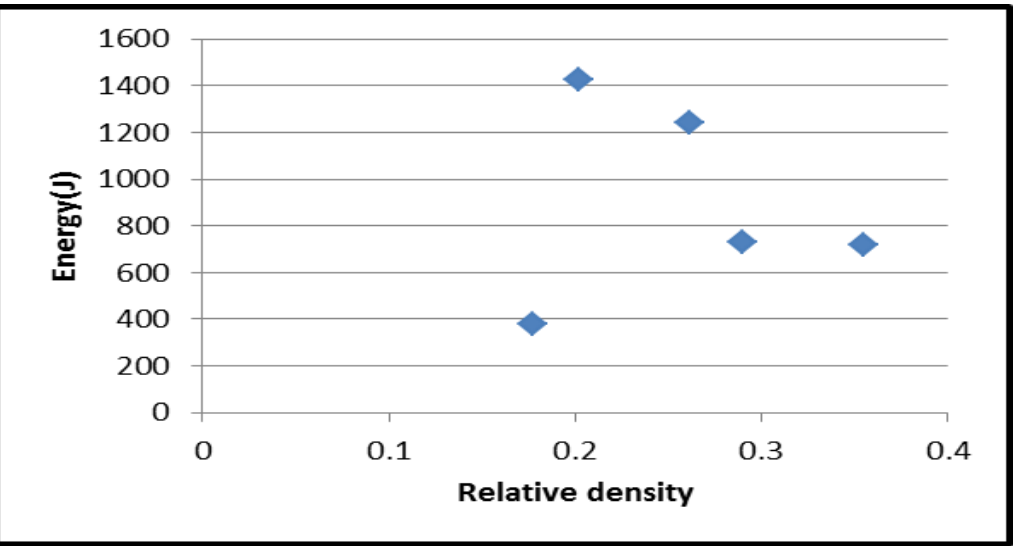

Fig. 13. Energy absorbed with relative density in dynamic test

The dynamic results shown in Fig (14) indicates that aluminum foam has a tendency to absorb more energy in case of dynamic loading compared to energy absorbed in case of static loading. This is mainly due to the fact that the speed of the wave increases above

Journal of Engineering Sciences, Assiut University, Faculty of Engineering, Vol. 41, No. 5, September, 2013, E-mail address: jes@aun.edu.eg 
A. A. Hussein, et al., Characteristics of Aluminum Form under Different Loading Rates, pp. 1830 - 1841 the critical deformation speed of the material. All material become brittle as the load propagation speed exceeds the critical deformation speed of the material .This transfer the aluminum wall from ductility into more strong and hard performance. Also the wave dispersion mechanism increases with the increase in wave speed and magnitude because higher reflected waves are to be counter the main incident wave in a harder performed material.

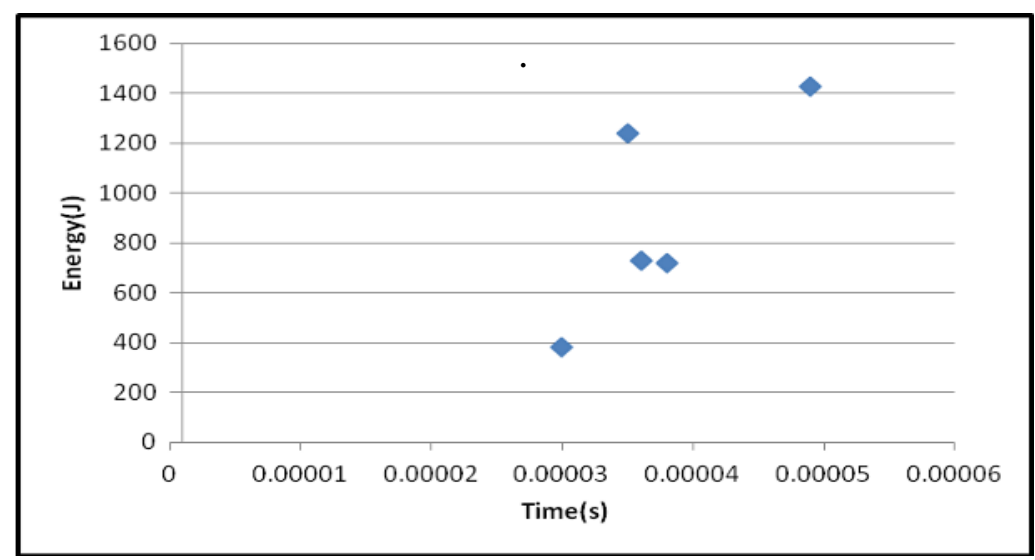

Fig. 14. Absorbed energy versus time for specimen tested under dynamic loading conditions

\section{Conclusions}

Aluminum foam produced using calcium carbonate, as a foaming agent, is an economical process for producing aluminum foam. Dynamic and static compression tests were conducted to characterize the mechanical properties of the produced aluminum foam. The results of the quasi-static loading condition showed that the energy absorbed increases with the increase of foam density which indicate that aluminum foam is not a competitive construction material under static loading conditions. While at dynamic loading condition the energy absorbed decreases with the increase in relative density. This trend clarify the benefit of aluminum foam as energy absorbing material at dynamic loading range and the fact that the decrease in foam density enhance the aluminum foam load carrying capacity. Also the dynamic test results showed that aluminum foam show a tendency to absorb more energy as the loading increases.

\section{References}

[1] Ilgaz Akseli, "The application of aluminum foam for the heat and noise reduction in automobiles", MSc thesis, the Graduate School of Engineering and Sciences of Đzmir Institute of Technology, 2005.

[2] M.F. Ashby, A.G. Evans, N.A. Fleck, L.J. Gibson, J.W. Hutchinson and H.N.G. Wadley, "Metal Foams: A Design Guide", Butterworth-Heinemann, 2000.

[3] N.Babcsan 1, J.Banhart1, and D.Leitlmeier:"metal foams-manufacture and physics of foaming" Int. conf advanced metallic meterials, smolenice, Slovakia,2003, pp 5-15.

[4] J.Banhart:"Manufacture, characterization and application of cellular metals and metal foams ", prog. master. sci., 2001, 46, pp 559-362.

[5] H.PDegischer" handbook of cellular metals", WILEY-VCH-Verlag foreword, 2002.

Journal of Engineering Sciences, Assiut University, Faculty of Engineering, Vol. 41, No. 5, September, 2013,E-mail address: jes@aun.edu.eg 
[6] V. Gergely and T.W Clyne, "The form grip process: foaming of reinforced metals by gas release in precursors ", Adv. Eng . mater, 2000, 2, pp175-178.

[7] A.R. Kennedy and S. Asavavisitchai, "Effects of TiB2 particle addition on the expansion, structure and mechanical properties of PM Al foams", Script Material, 2004, 50, pp 115-119.

[8] S.W .IP, Y.Wang and J.M Toguri,"Aluminum foam stabilization by soild particles", can. Met.Q. 1999, 38, PP 81-92.

[9] V.Gergely, 1.Jones and T.W.Clyne "The effect of capillarity-driven melt flow and size of particles in cell faces on melt foam structure evolution ", Trans. JWRI., 2001, 30. PP 371376.

[10] O.Parkash, H.sang and J.D Embur," structure and properties AL-Sic foam", Mater. Sci. Eng. A, 1995, 199, PP 195-203.

[11] J.A. Liu,S.R .Yu,Z.Q.Hu,Y.H.Liu and X.Y.Zhu ,"Deformation and energy absorption characteristic of Al2O3/Zn-Al composite foams during compression", Journal of alloys and compounds 2010, 506, pp 620-625.

[12] Jiaan Liu a, Sirong Yu a, Xianyong Zhu b, Ming Wei a, Song Li c, Yanru Luo b and Yaohui Liu:"Effect of Al203 short fiber on the compressive properties of Zn-22Al foams" Materials Letters, 2008, 62, pp3636-3638.

[13] V. Gergely, D.C. Curran and T.W. Clyne, " The FOAMCARP process: foaming of aluminum MMCs by the chalk-aluminum reaction in precursors", Composites Science and Technology, 2003, 63, pp 2301-2310.

[14] Marco Haesche , Dirk Lehmhus1, JÄorg Wsise, Manfred wichmann and Irene Cristina Magnabosco mocellin :",Carbonates as foaming agent in chip-based aluminium foam precursor", J.Mater. sci. technol., 2010, 26(9), pp 845-850.

[15] Nawal E.Abdullatef and Adel Mohammad: "Preparation of Al-12Si foam using Liquid Technique", Eng.\& Tech. Journal, 2009, 27(12), pp 24792493 vol.27, No.12,2009Eng.\&Tech.Journal,vol.27,No.12,2009.

[16] R.sharkawi, "Production of Aluminum Foam and the effect of calcium carbonate as a foaming agent", Journal of engineering sciences , assiut university, vol.39, No2, pp.441-451, March 2011.

[17] R. Edwin Raj a, Venkitanarayanan Parameswaranb, B.S.S. Danielc, "Comparison of quasistatic and dynamic compression behavior of closed-cell aluminum foam," Materials Science and Engineering A 526 (2009) 11-15.

\section{خصائص الالومنيوم الرغوي تحت تأثير معدلات تحميل مختلفة}

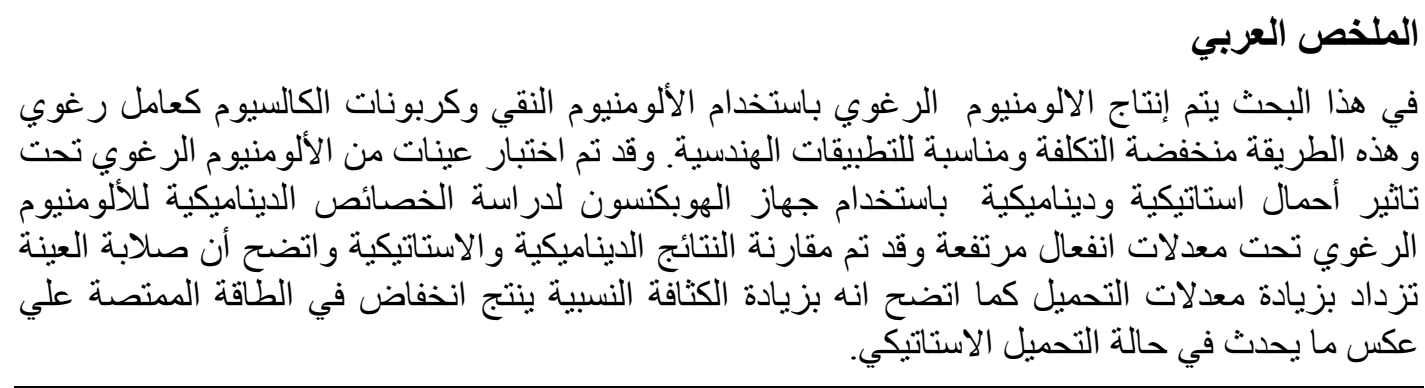

Journal of Engineering Sciences, Assiut University, Faculty of Engineering, Vol. 41, No. 5, September, 2013, E-mail address: jes@aun.edu.eg 